\title{
Food and Water Consumption Reason For Exclusion From Statistics
}

National Cancer Institute

\section{Source}

National Cancer Institute. Food and Water Consumption Reason For Exclusion From

Statistics. NCl Thesaurus. Code C119835.

A rationale for excluding a particular data point or subject from the food and water consumption statistical analysis. 